\title{
Composition-Crystallinity-Property relations in Mg-M-O films
}

\author{
M Saraiva $^{1 *}$, R. Persoons ${ }^{2}$, and D Depla ${ }^{1}$ \\ 1 Department of Solid State Sciences, Research Group DRAFT, Ghent University, \\ Krijgslaan 281(S1), 9000 Ghent, Belgium \\ 2 Flemish Institute for Technological Research (VITO), Boeretang 200, 2400
} Mol, Belgium

\begin{abstract}
The crystallographic properties such as texture and the level of crystallinity are important issues for the application of thin films. A fundamental understanding of the thin film growth mechanism forms the key to tune these properties. To understand the transition from crystalline to amorphous noticed when changing the composition of oxide thin films, Mg-M-O thin films (with $\mathrm{M}=\mathrm{Al}, \mathrm{Cr}, \mathrm{Ti}, \mathrm{Zr}$ and $\mathrm{Y}$ ) were deposited using reactive magnetron sputtering. Because substituting $\mathrm{Mg}$ by $\mathrm{M}$ yields to vacancy formation, the observed transition can be compared to the crystalline-to-liquid transition noticed in the hard sphere model, when the packing density is changed. The hardness and the bang gap of the Mg-M-O were measured. Using the packing density, it is possible to decouple the influence of the crystallinity from the influence of the composition in the hardness and band gap of the thin films.
\end{abstract}

*Corresponding author (e-mail address: marta.saraiva@ugent.be) 


\section{INTRODUCTION}

Film properties and functionality depend crucially on the crystallinity, i.e. on whether a film is crystalline or amorphous. Amorphous films are in general less dense and thus exhibit inferior mechanical strength as compared to their crystalline counterparts. ${ }^{1}$ On the other hand, due to the absence of grain boundaries, amorphous films are less prone to diffusion, chemical attack oxidation and corrosion ${ }^{2}$. Furthermore, the lack of long-range order results in isotropic properties, which is frequently not the case for crystalline films. The combination of amorphous and crystalline structure in the same film can also be beneficial. This is the case in the so called nanocomposite films in which control of the relative size and separation of nanosized crystals embedded in an amorphous matrix can result in films with superior mechanical, electrical and tribological performance. ${ }^{3,4}$

Film synthesis at conditions of limited atomic assembly kinetics - realized at relatively low growth temperatures and large arrival rates of the film forming species - leads to amorphous structures in materials with relatively large crystallization energy barriers. ${ }^{5}$ Bombardment by energetic species frequently encountered in plasma-assisted physical vapour deposition techniques (e.g. magnetron sputtering) has also been shown to be crucial for the structure formation. ${ }^{6,7}$ Moreover, intentional and non-intentional addition of impurity species which segregate at the grain boundaries may hinder or promote grain growth and thus determine the structure formation. ${ }^{8,9}$ Another way to influence crystallinity is by mixing two materials that exhibit different crystalline structures. In the case of relatively low concentration of the impurity phase in the host lattice solid solution may form. However, further increase in the impurity phase content often leads to formation of amorphous structure. Although observed in many systems, the origin of the latter behaviour on a fundamental electronic level is still not understood. The presence of atoms with size and valence electron number different than that of the host atom may affect electronic charge distribution and consequently the bond strength 
and type. These factors are, in turn, known to be crucial for the stability of a certain atomic configuration.

Recently we have synthesized Mg-M-O films (M=Al, Cr, Ti, Y and $\mathrm{Zr}$ ) where valency and cation size of $\mathrm{M}$ were systematically varied and found that increase of the $\mathrm{M}$ content in the metal sublattice led to amorphous films. ${ }^{10}$ Using a simple geometrical model it was shown that this is result of the vacancy formation upon substitution of $\mathrm{Mg}$ by $\mathrm{M}$ in the metal sublattice. ${ }^{10}$ In the present study we employ the notion of packing density to understand the role of both valance electron number and size of the substitutional cation in the crystalline-toamorphous transition in $\mathrm{Mg}-\mathrm{M}-\mathrm{O}$ films. Moreover, a number of physical properties are studied and the composition-crystallinity-property relations are elucidated.

\section{EXPERIMENTAL PROCEDURE}

\section{A. Film growth}

$\mathrm{Mg}-\mathrm{M}-\mathrm{O}$ thin films were deposited by dual reactive magnetron sputtering in an $\mathrm{Ar}-\mathrm{O}_{2}$ atmosphere. Depositions were performed using two homebuilt unbalanced planar circular magnetrons placed at an angle of $90^{\circ}$ with respect to each other and each at an angle of $45^{\circ}$ with respect to the substrate. Both magnetrons were fixed on a linear translator, allowing invacuum modification of the target-to-substrate distance. One magnetron was permanently equipped with a $\mathrm{Mg}$ target while in the other one several metallic targets $\mathrm{M}(\mathrm{M}=\mathrm{Al}, \mathrm{Cr}, \mathrm{Ti}, \mathrm{Y}$ and $\mathrm{Zr}$ ) were mounted. All targets were $5 \mathrm{~cm}$ in diameter and $3 \mathrm{~mm}$ in thickness, with a purity of at least $99.95 \%$ (Kurt Lesker). The magnetrons were fed by a PFG 1500 DC Hüttinger power supplies. More details on the experimental setup can be found in a previous report ${ }^{11}$. Films were deposited on RCA-cleaned silicon (100) substrates covered by a $\sim 2 \mathrm{~nm}$ native $\mathrm{SiO} 2$ layer. The substrates were fixed on a grounded substrate holder without intentional heating or cooling. A fixed argon pressure of $0.8 \mathrm{~Pa}$ was used for all depositions. Both 
magnetrons were operated at a constant current mode. The current for the magnetron permanently equipped with the $\mathrm{Mg}$ target was $0.5 \mathrm{~A}$. For the other magnetron, current $\left(\mathrm{I}_{\mathrm{d}}\right)$ values $I_{d, A l}=0.7 \mathrm{~A}, I_{d, C r}=0.5 \mathrm{~A}, I_{d, T i}=0.7 \mathrm{~A}, I_{d, Z r}=0.8 \mathrm{~A}$ and $I_{d, Y}=0.8$ A were used. $\mathrm{Mg}-\mathrm{M}$ $\mathrm{O}$ films with compositions ranging from pure $\mathrm{MgO}$ to pure $\mathrm{M}_{\mathrm{x}} \mathrm{O}_{\mathrm{y}}$ were grown by changing the target-to-substrate distance. The $\mathrm{O}_{2}$ flow was introduced locally at the substrate to ensure deposition of fully oxidized films while operating in the metallic sputtering mode. The deposition time was varied in order to obtain films with a thickness of $\sim 1 \mu \mathrm{m}$ as determined by a Talystep (Taylor-Hobson) profilometer.

\section{B. Film characterization}

The effect of the deposition conditions on the chemical composition was studied using an electron probe microanalyzer (EPMA) JEOL JXA-8621MX, with beam current of 30nA and voltage of $15 \mathrm{keV}$. Based on the determined composition, the metal sublattice composition is defined as $\mathrm{M} /(\mathrm{M}+\mathrm{Mg})$, e.g. $19 \% \mathrm{Cr}$ refers to a sample with composition $\mathrm{Mg}_{0.81} \mathrm{Cr}_{0.19} \mathrm{O}_{1.095}$. The crystallographic properties were evaluated by X-ray diffractometry (XRD). XRD measurements were performed in Bragg-Brentano $(\theta / 2 \theta)$ geometry with a LynxEye Silicon Strip detector mounted into a D8 discover apparatus (Bruker axs), which also has a quarter Eulerian cradle. This apparatus was also used to perform the pole figures measurements in combination with a Sol-X Energy dispersive X-ray detector. In the pole figures measurements, $\chi$ (the polar angle) and $\varphi$ (the azimuthal angle) were varied from $0-80^{\circ}$ and 0 $360^{\circ}$, respectively, in steps of $2^{\circ}$. The microstructure was studied by means of high resolution transmission electron microscopy (HRTEM). Details about sample preparation and operation conditions of TEM can be found elsewhere. ${ }^{12}$

The hardness of the films was determined by nano-indentation. Measurements were carried out in a Micro Materials apparatus using a Berkovitch tip. Indentations were made to a 
penetration depth of $100 \mathrm{~nm}$ into the samples. The hardness was calculated using the Oliver and Pharr method. ${ }^{13}$

Optical transmission measurements were performed with a UV-VIS-NIR spectrophotometer (Varian Cary 500). Some films (with large band gap) were measured in a VUV frequency range, which experimental setup consists of an ARC type DS-775 deuterium discharge lamp, a monochromator (ARC, model VM502 with 1200 grooves $/ \mathrm{mm}$ blazed at $250 \mathrm{~nm}$ with $\mathrm{Al} / \mathrm{MgF} 2$ coating for high reflectivity in the VUV region) and an EMI 9426 photomultiplier tube with $\mathrm{MgF} 2$ window. From the transmission spectra is possible to retrieve the absorption coefficient, which allows to calculate the fundamental band gap. The relation between the absorption coefficient and the incident photon energy $(h v)$ can be written as

$$
(\alpha h v)^{1 / n}=A\left(h v-E_{g}\right)
$$

where $A$ is a constant, $E_{g}$ denotes the band gap of the material and the exponent $n$ depends on the type of transition. For a direct allowed transition, $n$ is equal to $1 / 2$. Extrapolating the linear part of the graphic to the $h v$ axis, the direct band gap is obtained from the interception on the $h v$ axis.

\section{RESULTS AND DISCUSSION}

\section{A. Crystallographic properties}

\section{Crystalline-to-amorphous transition}

We have recently reported that addition of a metal $\mathrm{M}$ to the $\mathrm{MgO}$ films leads to the decrease in their crystallinity. In addition, for the crystalline films, an increase of the fraction of a metal $\mathrm{M}$ in the $\mathrm{Mg}-\mathrm{M}$-O films results in solid solution where $\mathrm{M}$ occupies octahedral sites along with

$\mathrm{Mg}$. This was manifested by a decrease in the intensity of the $\mathrm{MgO}$ reflections in the BraggBrentano XRD patterns (not shown here) and a decrease of the measured intensity in the (200) 
pole figures. ${ }^{10} \mathrm{~A}$ set of pole figures for the $\mathrm{Mg}-\mathrm{Al}-\mathrm{O}$ system, where the $\mathrm{Al}$ metal content varies from 15 to $52 \%$, is reproduced in Fig. 1 for reference. The intensity of the six poles (see crosses in Fig. 1 (a)) decreases with increase of $\mathrm{Al}$ metal content, being the films with $\mathrm{Al}$ content higher than $39 \%$ amorphous. To quantify the change of crystallinity upon M incorporation we calculate here a crystallinity factor, $C$, using the formalization presented in Ref. 10. The factor $\mathrm{C}$ is equal to the ratio between the integrated intensity measured for the $\mathrm{Mg}-\mathrm{M}-\mathrm{O}$ pole figure and the integrated intensity measured for the pure $\mathrm{MgO}$ film. Both intensities are normalized using as reference the intensity recorded in a pole figure of a purely amorphous alumina film. In addition to the formalization described in Ref. 10, the crystallinity factor in the present study takes also into account the defocusing effect of the xray detector ${ }^{14}$ and changes in the atomic scattering factors ${ }^{15}$ due to the substitution of $\mathrm{Mg}$ by M. The results of the analysis are summarized in Fig.2. There, it is seen that a transition from fully crystalline $(C=1)$ to fully amorphous $(C=0)$ films takes place when $\mathrm{M}$ content is increased. This transition occurs rather abruptly for all the systems, being all the films with $\mathrm{M}$ content higher than $50 \%$ amorphous. For some samples $C$ values larger than 1 are found. We attribute this to an increase of the film density when the M magnetron source is brought closer to the substrate, in order to change the film composition.

\section{A model to explain the transition}

It is known that the structure formation in thin films is determined by both surface diffusion and structure stability. Studies on $\mathrm{Mg}-M-\mathrm{O}$ films have shown that all crystalline films exhibit features of zone $\mathrm{T}$ microstructure (biaxial paper), i.e. V-shaped columns close to the filmsubstrate interface and faceted columns close to the film surface. In addition, all crystalline films are biaxial aligned (biaxial paper). These findings indicate that the microstructure and texture of the films is kinetically constrained. Along the same lines, one would expect that the transition from crystalline-to-amorphous would be induced by changing energy barriers due to 
the substitution of $\mathrm{Mg}$ by another cation. Nonetheless, there are a few points which are not consistent with this argument. The crystallite size, calculated for all $\mathrm{Mg}-M-\mathrm{O}$ systems using the Scherrer's formula, ${ }^{16}$ was found to be inversely proportional to $C_{M}$, with the slope independent of $\mathrm{M}$ (except for $\mathrm{Y}$ ). It would be surprising that the thin film growth kinetics hardly depends on the nature of the substituting cation, taking into account that several cations were studied. Furthermore, it is known that the presence of impurities which solubilize in the lattice do not influence the growth mechanism. ${ }^{8,9}$ Another argument is that the transition from crystalline-to-amorphous occurs quite abruptly, i.e., the crystallinity drops dramatically within a narrow range of $C_{M}$. These facts point to a structural reason for the transition. As in the $\mathrm{Mg}$ M-O films the bond strength of the M-O bonds is, for all metals $\mathrm{M}$, in the same order of magnitude $(-530+/-100 \mathrm{~kJ} / \mathrm{mole})$, it is not expected that incorporating $\mathrm{M}$ in the metal sublattice accounts for the observed transition. On the other hand, the substitution of $\mathrm{Mg}$ by $\mathrm{M}$ introduces metal vacancies, which introduces disorder, hampering the crystal formation and yielding to amorphous thin films. A correlation between disorder and structural stability has been described by the hard sphere model. ${ }^{17-19}$ The latter predicts that when the packing density is slowly decreased from the densest packing as defined by the Kepler conjecture, i.e. $\rho=\pi / \sqrt{18}$, to lower values, a first order transition from a crystalline state to a liquid state occurs at a packing density of 0.545 . When the packing density increases, the transition from liquid to crystalline case occurs at a packing density of 0.494 . This indicates that packing density values in the range of 0.494 and 0.545 define a boundary region where liquid and crystalline phases co-exist. The solid-to-liquid is a first order transition. The same is claimed for the crystalline-to-amorphous transition as has been discussed extensively in the literature. ${ }^{19}$ The abruptness of the transition in the hard-sphere model agrees with experimental noticed transition in the $\mathrm{Mg}-M-\mathrm{O}$ films. To test the hypothesis that the crystalline-to-amorphous transition is based on the introduction of vacancies, i.e. disorder, a 
model based on the hard-sphere model has been developed, and is discussed below. The model allows plotting the thin film properties in a different way, yielding the decoupling of the composition from the microstructure influence on the $\mathrm{Mg}-M-\mathrm{O}$ thin film properties.

The $\mathrm{MgO}$ structure can be described as a dense packed configuration of $\mathrm{O}^{2-}$ anions where $\mathrm{Mg}^{2+}$ cations occupy octahedral positions, see Fig. 3 (a). If a fictitious sphere with the same radius as $\mathrm{O}^{2-}$ is defined around each octahedral position (shown in Fig. 3(a)), those spheres will also form a dense packed configuration. Substitution of $\mathrm{Mg}$ by a metal $\mathrm{M}$ with a larger valence number leads to the generation of vacant octahedral positions, in order to maintain charge neutrality over the crystal (see Fig.3 (b)). When Mg is replaced by a cation M with the same valency but different ionic radius, the radius of the fictitious spheres will also increase, as shown in Fig.3 (c). In the current study all the substitutional cations have a different radius and different valence number than $\mathrm{Mg}$, inducing both changes in the radius of the fictitious spheres and creation of vacancies, as illustrated in Fig. 3 (d).

The composition of the metal sublattice in the studied Mg-M-O systems can be described by the form,

$\left[\begin{array}{ll}M_{x} & M_{1-x}\end{array}\right] \Phi_{\frac{n-2}{2}(1-x)} O_{\frac{2 x+n(1-x)}{2}}$,

where $x$ is the $\mathrm{Mg}$ content, $n$ is the valency of $\mathrm{M}$ and $\Phi$ represents the vacancies in the lattice. As mentioned in the beginning of the current section the grown films are solid solutions of $\mathrm{MgO}$ with $\mathrm{M}$ replacing the cation, therefore Eq. (2) can be rewritten as,

$M g_{\frac{2 x}{2 x+n(1-x)}} M_{\frac{2(1-x)}{2 x+n(1-x)}} \Phi_{\frac{(n-2)(1-x)}{2 x+n(1-x)}} O_{1}$,

which is a straightforward demonstration of the interplay between metal content and vacancies, when the metal composition is changed. As an example when $x$ is 1 (pure $\mathrm{MgO}$ ) there are no vacancies in the system, while when $x$ is 0 (for a $\mathrm{M}^{3+}, \mathrm{Al}_{2} \mathrm{O}_{3}$ ) $1 / 3$ of the metal sites is vacant. 
To compare the vacancy formation in the $\mathrm{Mg}-\mathrm{M}-\mathrm{O}$ thin films with the hard sphere model, it is needed to calculate the packing density related to a given film composition. Therefore, a good description of the Mg-M-O unit cell volume is needed. The latter can be calculated from the XRD measurements for the crystalline thin films. We have assumed that the same trend is followed for the amorphous thin films.

The Mg-M-O packing density is equal to the volume occupied by the fictitious spheres divided by the cell volume. The number of atoms within the unit cell can be determined by the chemical composition. This is illustrated by Eq. (3) which shows that per formula unit the fraction of filled octahedral positions, i.e. the number of fictitious spheres is equal to $2 /[2 x+n(1-x)]$. Although the substitution of $\mathrm{Mg}$ by $\mathrm{M}$ induces variations in the packing density of the fictitious spheres due to changes in the cation radii and due to the creation of vacancies, the hard sphere model only takes into account the changes in packing density resulting from vacancy formation. Therefore, the effect of change in radius in the packing density had to be eliminated. In the case that $\mathrm{Mg}$ is substituted by an atom different in size than $\mathrm{Mg}$, the radius for the fictitious sphere will change by $r_{M^{-}} r_{M g}$, being $r_{M}$ and $r_{M g}$ the radius of the metal $\mathrm{M}$ and $\mathrm{Mg}$, respectively, as compared to the radius of the sphere in the $\mathrm{MgO}$ crystal. Therefore, the weighted average radius of the fictitious sphere (which is used for the calculation of the occupied volume) for a $\mathrm{Mg}$ content $\mathrm{x}$ will be given by the expression

$$
r_{f s}=\frac{r_{O}+\left(r_{M g} x+r_{M}(1-x)\right)}{r_{O}+r_{M g}} \times r_{O}
$$

where $r_{f s}$ and $r_{O}$ are radius of the fictitious sphere and $\mathrm{O}^{2-}$ anion, respectively. ${ }^{20}$

To understand the influence of the packing density on the crystalline-to-amorphous transition observed for the Mg-M-O films, the crystallinity was plotted as a function of the packing 
density. By using the initial fictitious sphere radius as fitting parameter, all the $\mathrm{Mg}-\mathrm{M}-\mathrm{O}$ systems can be matched on one graph, as exhibited in Fig. 4. The error on the initial fictitious sphere radius is not larger than $3 \%$. The solid line in the plot is guide to the eye.

The phase boundary region, predicted by the hard sphere model, is indicated by the grey shadowed area. On the right side of this area, films with a high crystallinity are found. When lowering the packing density and entering the transition region, the crystallinity factor decreases abruptly. Films with a packing density lower than 0.494 have an insignificant crystallinity or are completely amorphous. HRTEM measurements were performed for the films marked with purple circles in Fig. 4 (a). Fig. 4 (b) shows a representative HRTEM image, for the thin film with $18 \% \mathrm{Y}$ metal ratio, where the presence of nanocrystals within an amorphous matrix can be seen. This finding is consistent with the suggestion of two phases in equilibrium predicted by the hard-sphere model. Based on these facts, one can conclude that the hard sphere model is valid to explain the crystalline-to-amorphous transition observed in the Mg-M-O films.

\section{B. Mechanical and optical properties}

\section{Dependency of the properties on the composition}

The hardness of the Mg- $M$-O films as a function of $M$ metal ratio is shown in Fig. 5 (a). The pure $\mathrm{MgO}$ film has a hardness of $\sim 4 \mathrm{GPa}$, which is lower than the values reported in literature. ${ }^{21}$ For all Mg-M-O system, the hardness of the films increases upon incorporation of M, up to a M metal content of $\sim 30 \%$. For $M$ content higher than $\sim 30 \%$, an increase of the $\mathrm{M}$ content either does not influence significantly the hardness of the films (Mg-Al-O and $\mathrm{Mg}-\mathrm{Cr}-$ O) or leads to a decrease of the films hardness (Mg-Ti-O, Mg-Zr-O and Mg-Y-O).In the case of the $\mathrm{Al}_{2} \mathrm{O}_{3}$ and $\mathrm{Y}_{2} \mathrm{O}_{3}$, the hardness of the studied films is similar to the values reported in 
literature, ${ }^{22,23}$ while for the other $\mathrm{M}$ oxides the values encountered in this work are lower than the reported ones. ${ }^{21,24-26}$

In Fig. 5 (b) the band gap as a function of the $M$ metal ratio for the $M g-M-O$ films can be seen. The band gap of the pure $\mathrm{MgO}$ is $6.74 \mathrm{eV}$, being in good agreement with reported values from other authors. ${ }^{27}$ Adding a $\mathrm{M}$ metal to $\mathrm{MgO}$ influences differently the band gap depending on the $\mathrm{M}$ element. The band gap of the Mg-Al-O films can be divided in three regions. Starting from pure $\mathrm{MgO}$ and up to an $\mathrm{Al}$ metal ratio of $\sim 30 \%$, the band gap of the films is approximately the same as the pure $\mathrm{MgO}$. Increasing the $\mathrm{Al}$ content in the films up to $60 \%$ leads to a decrease of the band gap (to $6.2 \mathrm{eV}$ ). Further increase of the $\mathrm{Al}$ induces a progressively increase of the band gap, reaching the $\mathrm{Al}_{2} \mathrm{O}_{3}$ film the same value as the pure $\mathrm{MgO}$. The band gap of the $\mathrm{Mg}-\mathrm{Cr}-\mathrm{O}$ films decreases upon increase of the $\mathrm{Cr}$ metal content. In the $\mathrm{Mg}-\mathrm{Cr}-\mathrm{O}$ series, two regions with different behaviors can be observed separated at $\mathrm{Cr}$ metal ratio $\sim 30 \%$. On the contrary to all the other systems, adding a small amount of $\mathrm{Ti}(\sim 9 \%)$ to $\mathrm{MgO}$ yields a significant decrease in the band gap (from 6.74 to $5 \mathrm{eV}$ ), while further increase of the $\mathrm{Ti}$ content induces a decrease of the band gap up to the pure $\mathrm{TiO}_{2}$ film $(3.57 \mathrm{eV})$ at a slower rate. The band gap behavior of the $\mathrm{Mg}-\mathrm{Zr}-\mathrm{O}$ films up to a $\mathrm{Zr}$ content of $60 \%$ is inversely proportional to the increase of the $\mathrm{Zr}$ content, while higher content of $\mathrm{Zr}$ results in a film with the same band gap as the pure $\mathrm{ZrO} 2(5.36 \mathrm{eV})$. The $\mathrm{Mg}-\mathrm{Y}-\mathrm{O}$ films have a similar behavior as the $\mathrm{Mg}-\mathrm{Zr}-\mathrm{O}$ films, being the band gap of the $\mathrm{Y} 2 \mathrm{O} 3$ slightly higher $(5.96 \mathrm{eV})$. The obtained values for the pure oxides are in good agreement with the literature. $^{27-31}$

\section{The influence of the crystallinity}

For all the materials the relation between the film properties (both hardness and band gap) does not exhibit a linear behavior with the film composition. Furthermore, it is known that 
besides the composition, the crystallinity also influences the film properties. By using the packing density, it is now possible to plot the properties as a function of a parameter related to crystallinity. This has two advantages. The first is a pure practical one, i.e., not all crystalline (or amorphous) films have the same X-coordinate in contrast to a property-crystallinity plot. The second advantage is the possibility to study the influence of the crystallinity. If the crystallinity has an important influence on a given property, we can expect that this property will change abruptly as function of the calculated packing density because also the crystallinity changes abruptly.

Within the crystalline and transition region (for packing density higher than 0.495), an increase of the hardness with the decrease of the packing density is observed (see Fig. 6 (a)). We have shown that the crystallite size of the $\mathrm{Mg}-M-\mathrm{O}$ films decreases with the increase of the M metal content (ref biaxial paper). Furthermore, in previous section it was demonstrated that within the packing density range of 0.495 to 0.7 the films are crystalline or nanocrystalline. Therefore, as there is an increase of the hardness with the decrease of the crystallite size, the Hall-Petch rule is followed. For films with packing density lower than 0.495 (within the amorphous region), the hardness behavior follows the rule of mixtures.

The band gap change in the $\mathrm{Mg}-\mathrm{Al}-\mathrm{O}$ and $\mathrm{Mg}-\mathrm{Cr}-\mathrm{O}$ films as a function of the packing density resembles the same behavior of the hardness. Two regions with respect to the slope can be identified for films with packing density larger than 0.495 (crystalline and nanocrystalline films), and films with packing density smaller than 0.495 (amorphous films). For the other systems, Mg-Ti-O, Mg-Zr-O and Mg-Y-O, there is no variation in the slope of the band gap change as a function of packing density, implying that crystallinity does not influence this property and it is rather determined by changes of the composition.

From Fig. 5 a non-monotonous behavior in the properties as a function of the composition can be seen which means that their change does not obey a simple rule of mixtures. The properties 
are affected by the chemical composition of the film and by its structure. Considering Figs. 5 and 6 one can conclude that the influence of the composition compared to the influence of the crystallinity in the properties is material and property dependent.

\section{CONCLUSIONS}

In conclusion, the substitutional effect on the crystallographic structure of $\mathrm{Mg}-M-\mathrm{O}$ thin films deposited by reactive magnetron sputtering is controlled by vacancy formation. The substitution of $\mathrm{Mg}$ by $M$ yields to vacancy formation, which is mimicked in the presented model by relating a hard-sphere to each filled octahedral position in the $\mathrm{MgO}$ structure. In this way, it is shown that these systems behave similar as a hard-sphere packing and a crystallineto-amorphous transition is induced for the same reasons. Furthermore, by using the packing density it is possible to decouple the influence of the crystallinity from the influence of the composition, distinguishing the regions and material systems where the composition (crystallinity) has a dominant influence in the properties of the films.

\section{ACKNOWLEDGMENTS}

The authors would like to acknowledge P. Smet for the VUV measurements. This work was conducted in the scope of the SBO project 60030, financially supported by the Institute for the Promotion of Innovation through Science and Technology in Flanders (IWT-Vlaanderen), Belgium. 


\section{BIBLIOGRAPHY}

J. Aarik, A. Kasikov, M. Kirm, S. Lange, T. Uustare, and H. Mandar, in Optical Materials and Applications, edited by A. Rosental (2005), Vol. 5946, pp. 94601. D.L. Smith, Thin film deposition, principles and practice. (McGraw-Hill, 1995). Joerg Patscheider, Niklas Hellgren, Richard T. Haasch, Ivan Petrov, and J. E. Greene, Physical Review B 83 (12) (2011).

Gert Gassner, Joerg Patscheider, Paul H. Mayrhofer, Saso Sturm, Christina Scheu, and Christian Mitterer, Tribology Letters 27 (1), 97 (2007).

M. Ohring, Materials Science of Thin Films, Deposition \& Structure. (Academic Press, 2002).

Stanislav Mraz and Jochen M. Schneider, Journal of Applied Physics 109 (2) (2011).

Stanislav Mraz and Jochen M. Schneider, Journal of Applied Physics 100 (2) (2006).

P. B. Barna and M. Adamik, Thin Solid Films 317 (1-2), 27 (1998).

I. Petrov, P. B. Barna, L. Hultman, and J. E. Greene, Journal of Vacuum Science \& Technology A 21 (5), S117 (2003).

M. Saraiva, V. Georgieva, S. Mahieu, K. Van Aeken, A. Bogaerts, and D. Depla, Journal of Applied Physics 107 (3), 034902 (2010).

M. Saraiva, H. Chen, W. P. Leroy, Mahieu S., N. Jehanathan, O. Lebedev, V. Georgieva, R. Persoons, and Depla D., Plasma Processes and Polymers, Accepted for publication (2009).

N. Jehanathan, V. Georgieva, M. Saraiva, D. Depla, A. Bogaerts, and G. Van Tendeloo, Thin Solid Films 519 (16), 5388 (2011).

W. C. Oliver and G. M. Pharr, Journal of Materials Research 7 (6), 1564 (1992).

Bob B. He, Two-Dimensional X-ray Diffraction, 2009 ed. (John Wiley \& Sons, Inc., New Jersey, 1954).

International Tables, Vol. C, pp. 500.

P. Scherrer, Nachr. Ges. Wiss. Göttingen 26, 98 (1918).

W. G. Hoover and F. H. Ree, Journal of Chemical Physics 49 (8), 3609 (1968).

Z. Nussinov, Physics 1, 40 (2008).

H. Reiss and A. D. Hammerich, Journal of Physical Chemistry 90 (23), 6252 (1986).

Bloss F. Donald, Crystallography and crystal chemistry : an introduction. (New York (N.Y.) : Holt, Rinehart and Winston, 1971).

D. Caceres, I. Vergara, and R. Gonzalez, Journal of Applied Physics 93 (7), 4300 (2003).

G. Alcala, P. Skeldon, G. E. Thompson, A. B. Mann, H. Habazaki, and K. Shimizu, Nanotechnology 13 (4), 451 (2002).

P. Yashar, J. Rechner, M. S. Wong, W. D. Sproul, and S. A. Barnett, Surface \& Coatings Technology 94-5 (1-3), 333 (1997).

Harish C. Barshilia and K. S. Rajam, Applied Surface Science 255 (5), 2925 (2008).

K. Goedicke, J. S. Liebig, O. Zywitzki, and H. Sahm, Thin Solid Films 377, 37 (2000).

P. J. Kelly, C. F. Beevers, P. S. Henderson, R. D. Arnell, J. W. Bradley, and H. Backer, Surface \& Coatings Technology 174, 795 (2003).

S. Ullah, A. H. Dogar, N. Mehmood, S. Hussain, and A. Qayyum, Vacuum, 509 (2009). 
P. Hones, M. Diserens, and F. Levy, Surface \& Coatings Technology 120, 277 (1999). W. T. Tang, Z. F. Ying, Z. G. Hu, W. W. Li, J. Sun, N. Xu, and J. D. Wu, Thin Solid Films 518 (19), 5442. S. B. Amor, L. Guedri, G. Baud, M. Jacquet, and M. Ghedira, Materials Chemistry and Physics 77 (3), 903 (2003).

L. Lou, W. Zhang, A. Brioude, C. Le Luyer, and J. Mugnier, Optical Materials 18 (3), 331 (2001). 


\section{CAPTION OF FIGURES}

FIG. 1. (color online) (200) pole figures of the series Mg-Al-O. Each pole figure shows the intensity of the $\mathrm{MgO}$ (200) Bragg reflection as a function of the sample orientation. As the thin films have a double in-plane orientation, six distinct poles are noticed (black crosses in figure 1a), as an example). When the Al concentration increases, the intensity of the poles starts to decrease. (a) $\mathrm{Mg}$ target-substrate distance $\left(\mathrm{d}_{\mathrm{Mg}}\right)=10.5 \mathrm{~cm}$, Al target-substrate distance $\left(\mathrm{d}_{\mathrm{Al}}\right)=18.5 \mathrm{~cm}, \mathrm{Al}$ metal ratio $(\mathrm{Al} /(\mathrm{Al}+\mathrm{Mg}) * 100)=15 \% ;(\mathrm{b}) \mathrm{d}_{\mathrm{Mg}}=10.5 \mathrm{~cm}, \mathrm{~d}_{\mathrm{Al}}=$ $16.5 \mathrm{~cm}, \mathrm{Al}$ metal ratio $=19 \% ;(\mathrm{c}) \mathrm{d}_{\mathrm{Mg}}=10.5 \mathrm{~cm}, \mathrm{~d}_{\mathrm{Al}}=14.5 \mathrm{~cm}, \mathrm{Al}$ metal ratio $=27 \%$; (d) $\mathrm{d}_{\mathrm{Mg}}=10.5 \mathrm{~cm}, \mathrm{~d}_{\mathrm{Al}}=12.5 \mathrm{~cm}, \mathrm{Al}$ metal ratio $=33 \% ;(\mathrm{e}) \mathrm{d}_{\mathrm{Mg}}=10.5 \mathrm{~cm}, \mathrm{~d}_{\mathrm{Al}}=10.5 \mathrm{~cm}, \mathrm{Al}$ metal ratio $=39 \%$; (f) $\mathrm{d}_{\mathrm{Mg}}=12.5 \mathrm{~cm}, \mathrm{~d}_{\mathrm{Al}}=10.5 \mathrm{~cm}, \mathrm{Al}$ metal ratio $=52 \%$.

FIG. 2. (color online) Crystallinity of the $\mathrm{Mg}-\mathrm{M}-\mathrm{O}$ films as a function of the $\mathrm{M}$ metal content.

FIG. 3. (color online) a) Schematic representation of the $\mathrm{MgO}$ structure ((200) plan) either as a dense packing of oxygen anions, or as a dense packing of fictitious spheres related to the $\mathrm{Mg}$ cation, whose radius is the same as the oxygen anion. Schematic representation of the effects that affect the $\mathrm{MgO}$ structure: b) This transition represents the creation of a metal vacancy in the $\mathrm{MgO}$ structure. c) The hypothetic

substitution of all $\mathrm{Mg}^{2+}$ by another cation with a larger radius, which results in a larger fictitious sphere than in the first schematic; d) When replacing $\mathrm{Mg}^{2+}$ by $\mathrm{M}^{\mathrm{n}+}$ (combination of b) and c) ), the size of the unit cell is affected (because of the replacement of $\mathrm{Mg}^{2+}$ with a cation of larger radius) and there is formation of vacancies. The change in the lattice parameter depends on the amount of $\mathrm{Mg}^{2+}$ and $\mathrm{M}^{\mathrm{n}+}$ and on the radius of $\mathrm{M}^{\mathrm{n}+}$. 
FIG. 4. (color online) (a) Crystallinity of the deposited $\mathrm{Mg}-M-\mathrm{O}$ thin films as a function of the calculated packing density of the fictitious spheres, using the initial fictitious sphere radius as fitting parameter. The grey region corresponds to the phase boundary region between the amorphous and crystalline states, as described by the hard sphere phase diagram. The purple open circles indicate the samples which were studied with HRTEM. b) HRTEM image of a Mg-Y-O thin film with a composition of $18 \%$ metal ratio. The arrows indicate the amorphous regions.

FIG. 5. (color online) (a) Hardness of the deposited $\mathrm{Mg}-M-\mathrm{O}$ films as a function of the $M$ metal ratio; (b) Band gap of the deposited $\mathrm{Mg}-M-\mathrm{O}$ films as a function of the $M$ metal ratio.

FIG.6. (color online) (a) Hardness of the deposited $\mathrm{Mg}-M-\mathrm{O}$ films as a function of the packing density; (b) Band gap of the $\mathrm{Mg}-M-\mathrm{O}$ films as a function of the packing density. 